\title{
Using Acoustic Emission to Evaluate Fracture Toughness Energy Release Rate (GI) at Mode I Delamination of Composite Materials
}

\author{
Amir Refahi Oskouei ${ }^{1}$, Andrea Zucchelli2, \\ Mehdi Ahmadi ${ }^{3}$ and Giangiacomo Minak ${ }^{4}$ \\ ${ }^{1}$ Islamic Azad University, East Tehran Branch, \\ ${ }^{2,4}$ University of Bologna, \\ ${ }^{3}$ Amirkabir University of Technology (Tehran Polytechnic), \\ 1,3 Iran \\ 2,4 Italy
}

\section{Introduction}

Delamination is a critical damage mode in composite structures, not necessarily because it will cause the structure split into two or more pieces at the end of the damaging process, but because it can degrade the laminate strength to such a degree that it becomes useless in service. The design of composite structures to account for delamination and other forms of damage involves two fundamental considerations, namely damage resistance and damage tolerance. Knowledge of a laminated composite material's resistance to interlaminar fracture is useful for product development and material selection.

Damage resistance is the measure of the capability of a material or structure to resist the initial occurrence of damage. This aspect must be considered for designing and maintaining the integrity of load carrying structures (Pagano \& Schoeppner, 2000). In this regard, we should also note that polymer matrix composites are given primary attention because of their importance and dominance in practical structural applications as well as the composite literature itself.

Mode I inter-laminar fracture has received the greatest attention from researchers. This is due to the fact that the delamination initiation energy is low compared to that of the shearing mode. Several studies were already conducted on the mode I fracture to determine the surface energies of composite materials by creating a crack propagation effect (Perrin et al., 2003). Researchers were thus able to consider the effect of ambient conditions and manufacturing variables on the strain energy release rate $\left(\mathrm{G}_{\mathrm{I}}\right)$ (Velmurugan \& Solaimurugan, 2007). The effect of fiber direction on delamination fracture toughness is a problem that was studied by (Kim \& Mayer, 2003), and (Solaimurugan \& Velmurugan, 2008). Literature results show that adjacent ply delamination fracture toughness decreased as the mismatch angle of fiber between the same plies increased (MIL-HDBK, 2002). The reason for fracture energy dependence on 
fiber mismatch angle is considered to be the stiffness of the plies thus fibers have the highest contribution to the stiffness of each ply. The effects of temperature on delamination growth in a carbon/epoxy composite under fatigue loading also shows that at elevated temperatures the strain energy release rate threshold values for delamination growth under fatigue loading are significantly lower than the critical energy release rates in static tests (ASTM, 1994; Sjogren \& Asp, 2002). The effect of loading rate on fracture toughness of laminated composites was studied by (Kusaka et al., 1998) and (Hug, 2006). The results show a slight effect of loading rate on fracture toughness at rates up to 1.6 $\mathrm{m} / \mathrm{s}$, but beyond this rate threshold the fracture energy decreases (Benmedakhene et al., 1999). So far, many researchers have tried to improve delamination fracture toughness through different techniques. In some investigations, improvements in delamination fracture toughness were performed through 3D fiber architecture (stitching, knitting and braiding). It was observed that through thickness stitching is a promising reinforcing technique for improving interlaminar strength (Tsai \& Chen, 2005).

Some analytical and theoretical models simulated via finite element method (FEM) are also used for predicting interlaminar delamination in composite structures (Chen, 1999). The computed results have been very similar and in close agreement with both the experimental results and solutions obtained from a corrected beam theory (Diaz, 2007).

Based on the extensive and thorough literature investigation it can be concluded that mode I delamination tests depend on many parameters such as opening rate, fiber direction, type of resin, condition of resin, temperature, etc. Crack propagation can be defined as the ultimate form of failure mechanism taking place in the interlaminar zone during delamination. As can be evaluated by direct observation or using a load-displacement plot, this is a macroscopic failure activity. Microscopic behavior of fiber matrix interface microdamage is more difficult to be investigated, although it represents a major part of the delamination process. For monitoring microscopic events, Acoustic Emission (AE) is an appropriate tool (Refahi Oskouei \& Ahmadi, 2010; Ndiaye et al., 2000; R'Mili et al., 2008; Cesari et al., 2007; Huguet et al., 2002). However, the interpretation of the signals and, hence, the evaluation of the damage stages is a major problem of the AE method.

The combination of Double-cantilever beam (DCB) fracture-toughness tests with simultaneous AE monitoring provides useful information about microscopic and macroscopic aspects of the delamination process.

During the last 30 years, in few papers the AE has been considered as a tool to predict the delamination fracture toughness (Benmedakhene et al., 1999; Ndiaye et al., 2000; Niebergall et al., 1999; Bohse, 2000; Lorriot, Wu \& Dzenis, 2003; Bohse \& Brunner, 2008). Except the paper (Ndiaye et al., 2000), in all other works the mode I fracture toughness is estimated by conventional formulas provided by normative and the AE information are used to have a phenomenological description of the delamination progression. The paper presented by (Ndiaye et al., 2000) used the AE information to estimate the $\mathrm{G}_{\mathrm{Ic}}$, nevertheless their approach has some limitations concerning the theoretical approach and some details about that will be discussed later in the present paper.

From literature studies about delamination failure in composite laminate and its monitoring by $\mathrm{AE}$ three critical aspects can be listed: the first concerns how $\mathrm{AE}$ 
information is used to estimate the $\mathrm{G}_{\mathrm{Ic}}$, the second concerns the repeatability of the results and the application of the methodologies to different case studies, the third aspect concerns the comparison of the results obtained by using the AE information to the ones that can be obtained by the current standards, such as (ASTM, 1994). Regarding the first aspect, it can be noted that the classic way of using the AE information in order to estimate some of the relevant material performances (e.g. ultimate strength, fracture toughness, residual strength after damage) is based on empirical or semi-empirical relations where the mechanical and the AE information is used separately. In other words, in these studies the authors want to use the AE information as self-standing information to predict or estimate the mechanical performances. The results obtained from such studies are typically weak with respect to the repeatability and to the extension to case studies different from the one that is analyzed in the specific paper. The approach that is proposed and applied in the present study is based on a novel function that combines the mechanical and AE energies. This function is based on the idea that during the loading process a material is able to store strain energy and at the same time part of the stored energy is also released due to the internal failures. The AE events energy represents an important part of the released energy and can be used to weight the strain energy storing capability of the material. As greater is the damage due to internal failure as the cumulated AE increases and at the same time the strain energy storing attitude is reduced. The proposed function thus compares the strain energy stored in the material $\left(\mathrm{E}_{\mathrm{s}}\right)$ to the released energy in the form of acoustic energy $\left(E_{a}\right)$ by their ratio $\left(E_{s} / E_{a}\right)$. It was proved that the best way to represent such a ratio is to consider its natural logarithm $\left(\ln \left(E_{\mathrm{s}} / \mathrm{E}_{\mathrm{a}}\right)\right)$, (Minak \& Zucchelli, 2008). This function, called sentry function $f$, has been successfully applied to study the damage progression of some composite laminates (Minak \& Zucchelli, 2008), to estimate the static and the fatigue residual strength of a plate subjected to indentation processes (Cesari et al., 2007; Minak \& Zucchelli, 2008; Minak et al., 2009), and to estimate the residual torsional strength of a composite tube subjected to a lateral impact (Minak et al., 2009).

The purpose of the present study is to investigate the delamination mode I process of composite laminate in double cantilever beam (DCB) set-up by using the sentry function. Three types of specimens with different midplane layups, leading to different levels of interlaminar performance, were therefore studied. The use of the sentry function enabled the analysis of a test phase during which it was not possible to identify any visible crack propagation. Such analysis is of particular interest to determine the crack length evolution and consequently the $\mathrm{G}_{\mathrm{I}}$ variation during the test. In particular, it was possible to determine the test stage at which the crack propagation became visually detectable by means of the maximum value of the integral of the sentry function $(\operatorname{Int}(\mathrm{f}))$ that is a parameter used to estimate the material damage progression (Minak \& Zucchelli, 2008; Minak et al., 2009). The $\operatorname{Int}(\mathrm{f})$ is defined as the integral of the sentry function over the displacement domain where acoustic emission has been detected:

$$
\operatorname{Int}(f)=\int_{\Omega_{\mathrm{AE}}} f(x) d x
$$

Based on values of Int(f) it was possible to predict the test stage at which a delamination propagation becomes visible under an opening load condition. Furthermore, it was possible 
to highlight a bi-linear relation between the cumulative strain energy release rate (GICUM) and the integral of the sentry function over the displacement domain (Int(f)). The transition point in the bilinear relation enabled the estimation of the critical strain release rate $\left(\mathrm{G}_{\mathrm{Ic}}\right)$ value. The $\mathrm{G}_{\mathrm{Ic}}$ obtained by this approach was then compared to the values obtained by both ASTM D5528 standard test method (ASTM, 1994) and (Ndiaye et al., 2000) approaches. It was possible to obtain a very good agreement between the results from the new approach to the ones obtained by the ASTM D5528. At the contrary, a strong disagreement was noted between the results obtained by the Ndiaye approach with respect to the ones obtained by the new approach and the ASTM D5528 one.

\section{Experimental procedure}

\subsection{Material and specimen preparation}

The composite double cantilever beam (DCB) specimens used in this study are polyester resin reinforced with glass fiber. The properties of the polyester resin as a matrix material and fiber as a reinforcement are summarized in table 1 . Three different interface types were used: woven/woven (T3), woven/unidirectional (T4) and unidirectional/unidirectional (T5). The laminates were prepared by hand lay-up. The starter crack was formed by inserting a Teflon film with a thickness of $\sim 20 \mu \mathrm{m}$ at mid-plane during molding as an initial crack for the mode I interlaminar fracture toughness test. Fiber orientations were measured with respect to beam axis along the specimen length. The angular orientation of woven lamina was represented by the orientation of warp directional fibers. The specimen dimensions were width $b=20 \mathrm{~mm}$, crack length $a=70 \mathrm{~mm}$, total length $250 \mathrm{~mm}$, and thickness $2 \mathrm{~h}=5 \mathrm{~mm}$.

\begin{tabular}{|l|l|l|l|l|}
\hline Material & Density* & $\begin{array}{l}\text { Ultimate tensile } \\
\text { stress }(\mathrm{MPa})\end{array}$ & $\begin{array}{l}\text { Elastic modulus } \\
(\mathrm{GPa})\end{array}$ & $\begin{array}{l}\text { Tensile failure } \\
\text { strain (\%) }\end{array}$ \\
\hline Polyester resin & 1.12 & 80 & 2.7 & 3 \\
\hline Unidirectional glass fiber & 500 & 2150 & 74 & 2.6 \\
\hline Woven glass fiber & 292 & 2150 & 74 & 2.6 \\
\hline
\end{tabular}

*For polyester the unit of density is $\mathrm{g} / \mathrm{cm}^{3}$ and for glass fiber the areal or surface density is considered e.g. $\mathrm{g} / \mathrm{cm}^{2}$.

Table 1. Summary of matrix and fiber properties.

\subsection{Testing procedure}

The opening forces were applied to the DCB specimen with loading blocks (Fig. 1) bonded to one end of the specimen. The ends of the DCB were opened by controlling the crosshead movement. The tests were carried out with a displacement speed of $5 \mathrm{~mm} / \mathrm{min}$ for each specimen, while the load and delamination length were recorded. Both edges of the specimens just ahead of the insert were coated with a thin layer of water-based typewriter correction fluid and marked in accordance with ASTM D5528 standard instruction to aid in visual detection of delamination onset. Five specimens for each type of sample were used for the DCB test. 


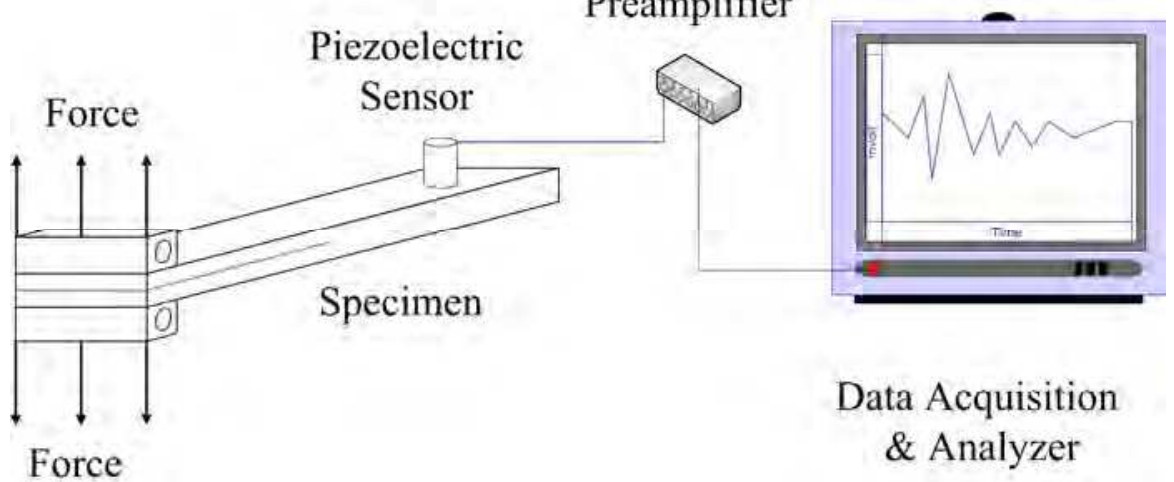

Fig. 1. View of the experimental device for AE monitoring of DCB specimen.

\subsection{AE equipment}

Acoustic emission software AEWin and a data acquisition system Physical Acoustics Corporation (PAC) PCI-2 with a maximum sampling rate of $40 \mathrm{MHz}$ were used to record AE events. A broadband, resonant-type, single-crystal piezoelectric transducer from PAC, called PICO, was used as the AE sensor. The sensor had a resonance frequency of $513.28 \mathrm{kHz}$ and an optimum operating range of $100-750 \mathrm{kHz}$. The surface of the sensor was covered with grease in order to provide good acoustic coupling between the specimen and the sensor. The signal was detected by the sensor and enhanced by a 2/4/6-AST pre-amplifier. The gain selector of the preamplifier was set to $40 \mathrm{~dB}$. The test sampling rate was $1 \mathrm{MHz}$ with $16 \mathrm{bits}$ of resolution between 10 and $100 \mathrm{~dB}$. Prior to the damage check, the data acquisition system was calibrated for each kind of specimen, according to a pencil lead break procedure. The pencil lead break procedure enables the generation of waves at the specimen surface that are used for the device calibration. At the same time, the velocity and attenuation of the AE waves were measured. The lead breakage operation was repeated several times and at different locations between the sensors. After the calibration step, AE signals were captured during mechanical testing. Signal descriptors, such as amplitude, duration, rise time, counts, and energy, were calculated by the AE software (AEWin).

\subsection{Energy release rate}

The beam theory expression for the strain energy release rate of a perfectly built-in (that is, clamped at the delamination front) double cantilever beam is as follows:

$$
G_{I}=\frac{3 P \delta}{2 b a}
$$

where $\mathrm{P}=$ Load,$\delta=$ load point displacement, $\mathrm{b}=$ specimen width and $\mathrm{a}=$ delamination length .

In practice, this expression will overestimate $G_{I}$ because the beam is not perfectly built-in (that is, rotation may occur at the delamination front). One way to overcome this problem is to apply a correction factor to the modified beam theory (MB) for the strain energy release 
rate. The ASTM D5528 standard introduces the correction factors $\mathrm{F}$ and $\mathrm{N}$ in order to account for the presence of the end blocks and for the large opening displacements obtained as the crack length $a$ increases (Equation (3)):

$$
G_{I}=\frac{3 P \delta}{2 b(a+|\Delta|)} \frac{F}{N}
$$

where $\Delta$ may be determined experimentally by generating a least-square plot of the cubic root of compliance, $\mathrm{C}^{1 / 3}$, as a function of delamination length. The compliance, $\mathrm{C}$, is the ratio of the load point displacement to the applied load, $\delta / P$. The values used to generate this plot should be the load and displacements corresponding to the visually observed delamination onset on the edge and all the propagation values. As $\mathrm{P}$ reaches its critical value, $P_{c}$, the crack starts propagating. The corresponding $G_{I}$ value is the critical energy release rate $G_{\text {Ic. }}$. The latter is considered to be a material characteristic that represents the fracture toughness of the cracked interface. Based on an energy criterion, $\mathrm{G}_{\mathrm{Ic}}$ yields an estimation of the amount of energy absorbed during crack growth until the delamination size reaches the critical length.

\subsection{Sentry function}

The sentry function is defined as the logarithm of the ratio between mechanical and acoustic energies and it can be formulated as follows:

$$
f(x)=\operatorname{Ln}\left(\frac{E_{s}(x)}{E_{a}(x)}\right)
$$

For the calculation of the two energies, two reference volumes were considered: the volume of the material where the strain energy is stored $\left(\mathrm{V}_{1}\right)$ and the volume where the delamination can propagate $\left(\mathrm{V}_{2}\right)$ and from which the AE events can take place. So, for the purpose of the analysis of the DCB tests, the strain energy, $E_{\mathrm{s}}$, was normalized over the bended volume joined with the cracked volume $\left(V_{1}+V_{2}\right)$ and the cumulative acoustic energy, $E_{a}$, was normalized over the cracked volume $\left(V_{2}\right)$, see Fig. 2.

As described in previous studies (Cesari et al., 2007; Minak \& Zucchelli, 2008; Minak et al., 2009; Minak et al., 2009), the function $f$ is defined over displacement domain where the acoustic energy Ea is non zero (see Fig. $3, \Omega_{\mathrm{AE}}$ ). Depending on the material damaging process, the resulting $f$ can assume any combination of the five trends shown in Fig. 3. From the physical point of view, the parts of $f$ characterized by an increasing trend, type I, represent the strain energy storing phases. When a significant internal material failure occurs, there is an instantaneous release of the stored energy that produces an AE event with high energy content. This fact is highlighted by the sudden drops of the function $f$ that can be described by type II functions: PII (x). The constant behavior of $f$, described by PIII, is due to a progressive strain energy storing phase that is superimposed on an equivalent energy release due to material damage progression. The subsequent Bottom-Up (BU) trend indicates that a strengthening event induced an instantaneous energy storing capability in the material. Such an event can be related to hardening effects, self-healing effects or, as in 
the case of the present study, it can be related to fiber bridging effects. The decreasing behavior of $f$, type PIV, is related to the fact that the AE activity is greater then the material strain energy storing capability: the damage has reached a maximum and the material has no resources to sustain the load. The $P_{I}$ and $B U$ functions both have an increasing trend. Both functions, according to the definition of the sentry function represent events that occur when the strain energy storing capability exceeds the energy release (that is, in this procedure, measured by the acoustic energy). This means that if the material is able to store energy during the test, the sentry function can be described by a function of type I or a BU function type. In the case of moderate material damage, always at the beginning of the testing process, the strain energy storing capability exceeds the amount of energy that is released and the sentry function is characterized by an increasing function, but, due to the fact that the damage in the material is growing, the slope of this function progressively decreases. On the other hand, if a strong material configuration change occurs, such as the when fibers between two adjacent plies create a connection, also called fiber bridging, the strain energy storing capability increases instantaneously. In such a case the sentry function can be described by a linearly increasing function as the BU function is. So, comparing the PI and the BU functions, it can observed that the first one is characterized by a decreasing slope and the BU function has an almost linear slope. Moreover the BU function has a lower extension than the $\mathrm{P}_{\mathrm{I}}$ one.

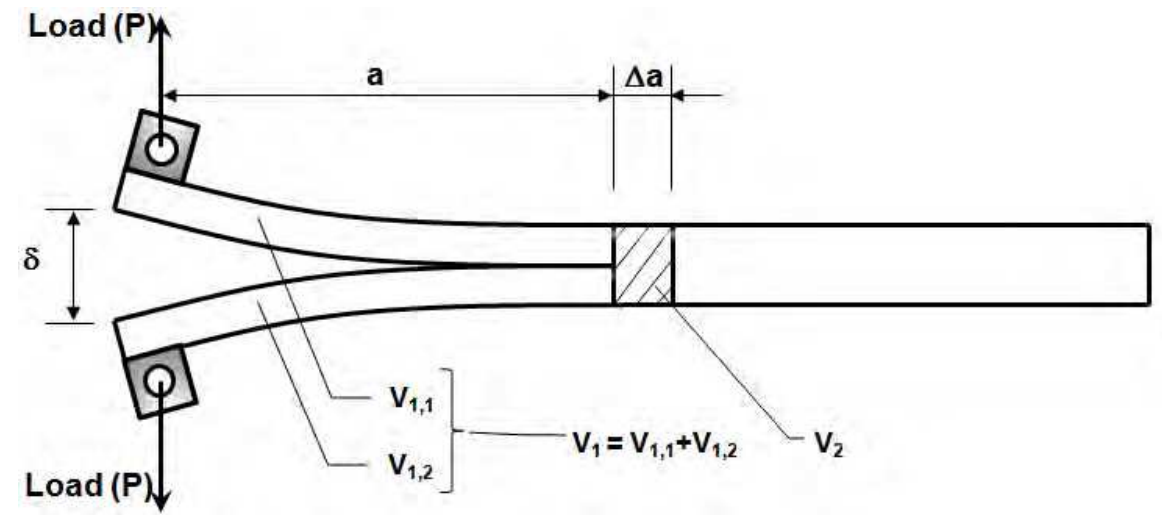

Fig. 2. Reference volume $V_{1}$ and $V_{2}$ for the normalized energies calculation.

\section{Results and discussion}

Results from DCB tests are reported in two main paragraphs: in the first one the mechanical behavior and the main AE information are reported, in the application of the sentry function to the studied specimens is presented.

\subsection{Mechanical behavior and AE trends}

Fig. 4 shows an example of the DCB specimen mechanical behavior in terms of loaddisplacement and crack length-displacement diagrams for each mid-plane interface type (the load was normalized by means of the specimen thickness) 
Referring to Fig. 4, it can be noted that at the beginning of loading, the load and displacement relation is almost linear until the maximum load. Beyond the maximum load, the nonlinearity is considerable. Also, the crack propagation initiates near the maximum load. Note that there is no visible crack propagation at the beginning of loading. Referring now to the crack length diagrams, the comparison of three plots in Fig. 4 shows that the specimen $\mathrm{T} 3$ has stable-like crack propagation and there is a smooth increasing curve during the loading after the maximum load. For specimens T4 and T5, the crack length curve development has a completely different trend. This is due to fiber bridging during the delamination process that affects the load-displacement curve. In some cases, before maximum load, fiber bridging has occurred and the kick points (sudden drop off in load) are highlighted in the load-displacement curve; however, such a physical phenomenon does not seem to have any effect on the crack length development. Moreover, the other conditions like crack jumping from one layer to another one and the cutting condition (cutting edge) are factors leading to kick point existence too.

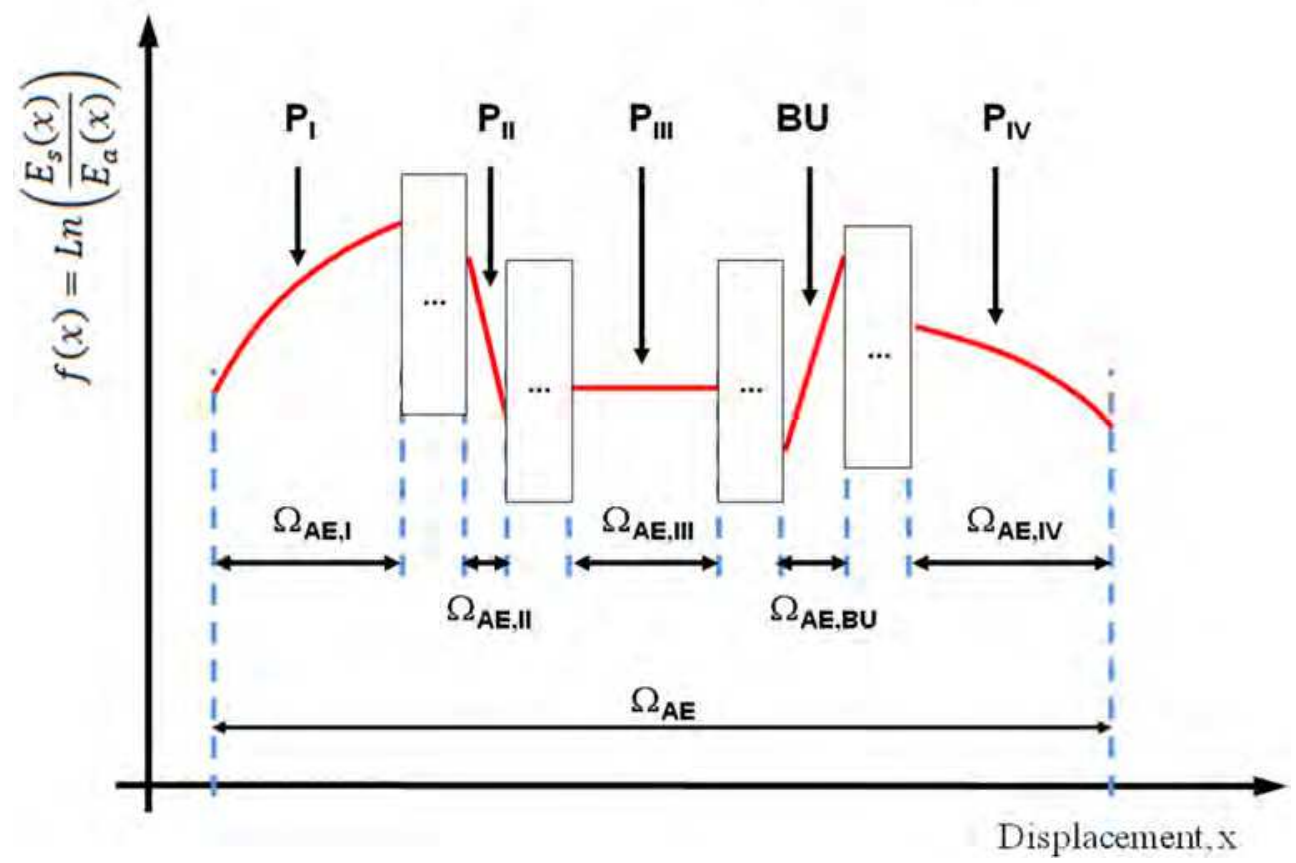

Fig. 3. The basic functions $\mathrm{P}_{\mathrm{I}}, \mathrm{P}_{\mathrm{II}}, \mathrm{P}_{\mathrm{III}}$ and $\mathrm{P}_{\mathrm{IV}}$, used to describe the function $f$.

Diagrams in Fig. 5 show the trend of the $G_{I}$ calculated by the formula (2) from the ASTM D5528 standard. From such diagrams it can be observed that up to maximum load the strain energy release rate is increasing, but beyond maximum load there is a slight decrease in the $\mathrm{G}_{\mathrm{I}}$ trend. Such reduced values of the strain energy release rate are related to the drop off of the load shown in the load-displacement diagram. The load drop off is due to the crack propagation process based on a sudden extension and a subsequent stop (the "stop and go" phenomenon). 
Fig. 6 summarizes some of the most relevant information extracted from the mechanical behavior. In particular, the load values which were considered are the maximum load and the load at which the first crack extension was visibly observed. Both values are useful for the subsequent calculation of the $\mathrm{G}_{\mathrm{I}}$. The displacement values at the maximum load and at the first observed crack extension are both useful to characterize the different behavior of the mid-plane interface quality with respect to mode I of delamination.
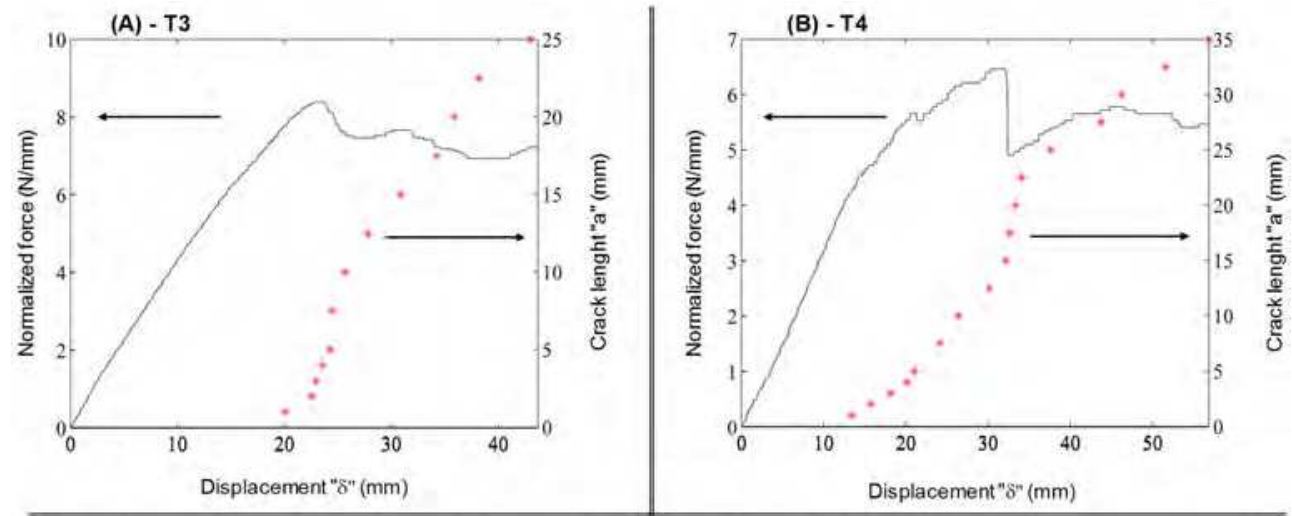

(C) - T5

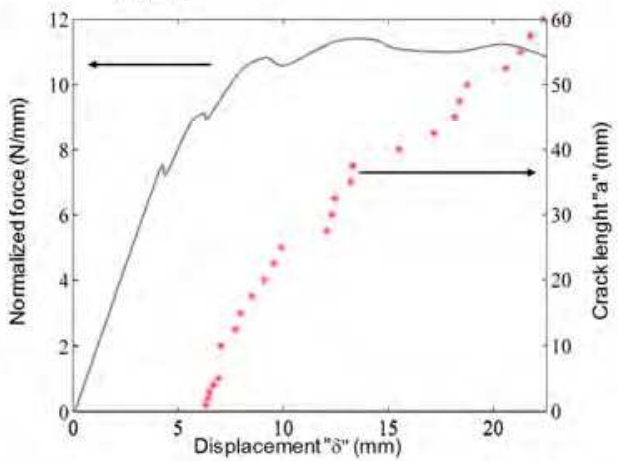

Fig. 4. Typical load and crack propagation length versus displacement for the three types of specimen mid-plane interfaces.

Fig. 7 shows the acoustic emission events behavior during loading. Different AE behaviors were noted between the different interface types and in particular great differences are highlighted where AE energies were first detected at the early stage of loading with alternating appearances up to an arbitrary delaminated length. Variations in AE event energy also reflect different damage mechanisms. The early stage of loading is free of acoustic events, but near the maximum load the first AE events are detectable. During the crack propagation process, the number of cumulative $\mathrm{AE}$ events and the cumulative $\mathrm{AE}$ event energy increase (Fig. 8). In particular, it can be seen that depending on the interface type the trend of cumulative events and of cumulative AE energy versus opening displacement change. It can thus be observed that at a fixed opening displacement in the case of the tougher interface, T5, 
the detected events are fewer than with the brittle one, T4, and the AE energy can vary because of different dominant damage mechanisms in each specimen.

A more detailed description of AE events can be obtained from Fig. 8 where the cumulative counts and AE event energy are plotted versus the displacement (in Fig. 8, the load and the $G_{I}$ are also reported in each diagram and all diagrams have the same horizontal scale). In particular, it can be noted that increasing the toughness of the interface, from T4 up to T5, the number of cumulative counts recorded at the visible crack propagation point and at the maximum load decreases.
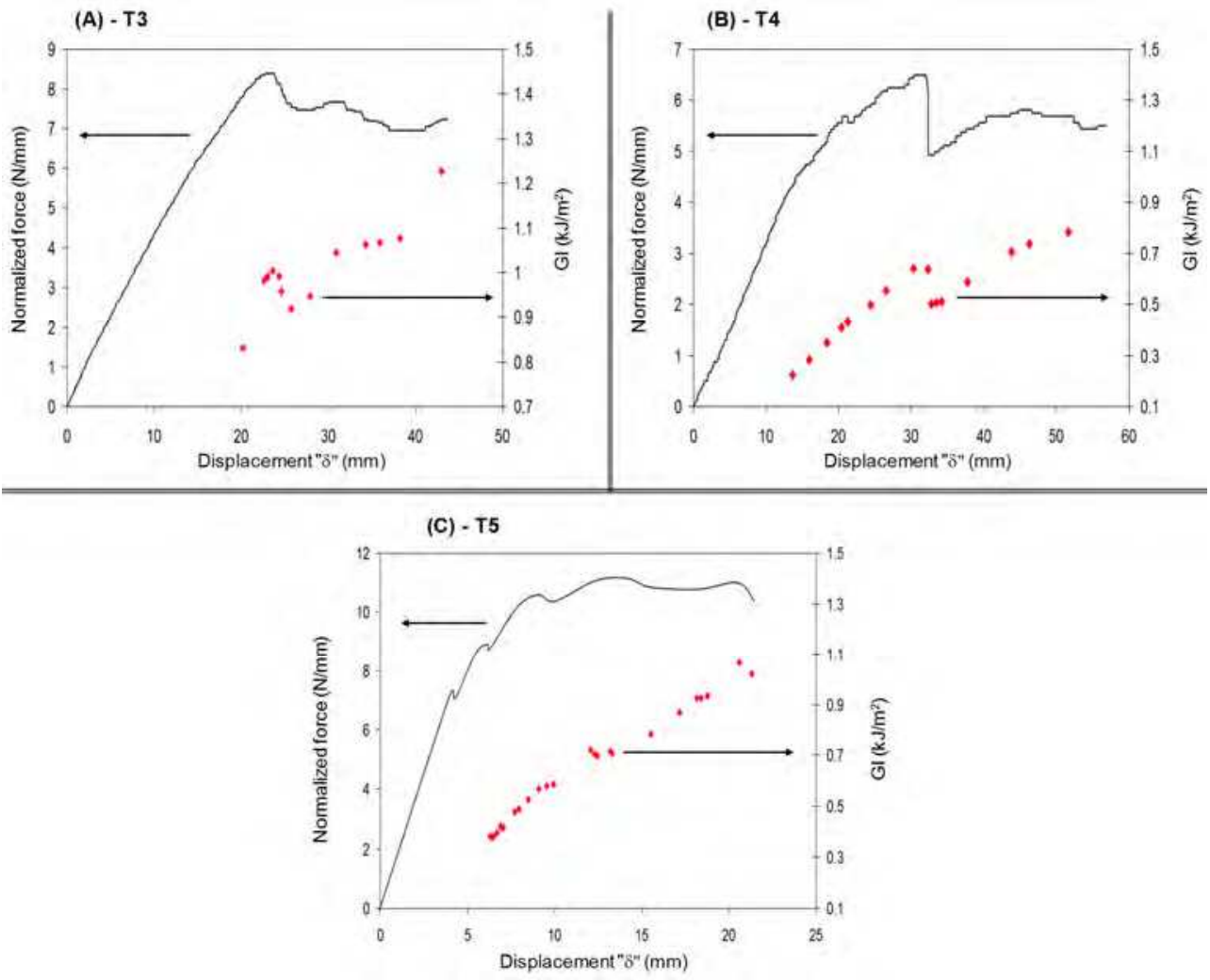

Fig. 5. Typical trends of load and $G_{I}$ versus displacement for the three mid-plane interfaces.

In particular, it is of interest to consider the number of cumulative counts (Count CUM) and the cumulative AE event energy (Ea CUM) at the first visible crack extension. These values are summarized in Table 2 in terms of mean value (M.V.) and coefficient of variation (C.V.) of cumulative counts and cumulative AE energy.

The data in Table 2 show that the Count CUM or the cumulative AE event energy are not useful variables to predict the test stage at which the first visible crack extension occurs because the coefficients of variation are too high. 


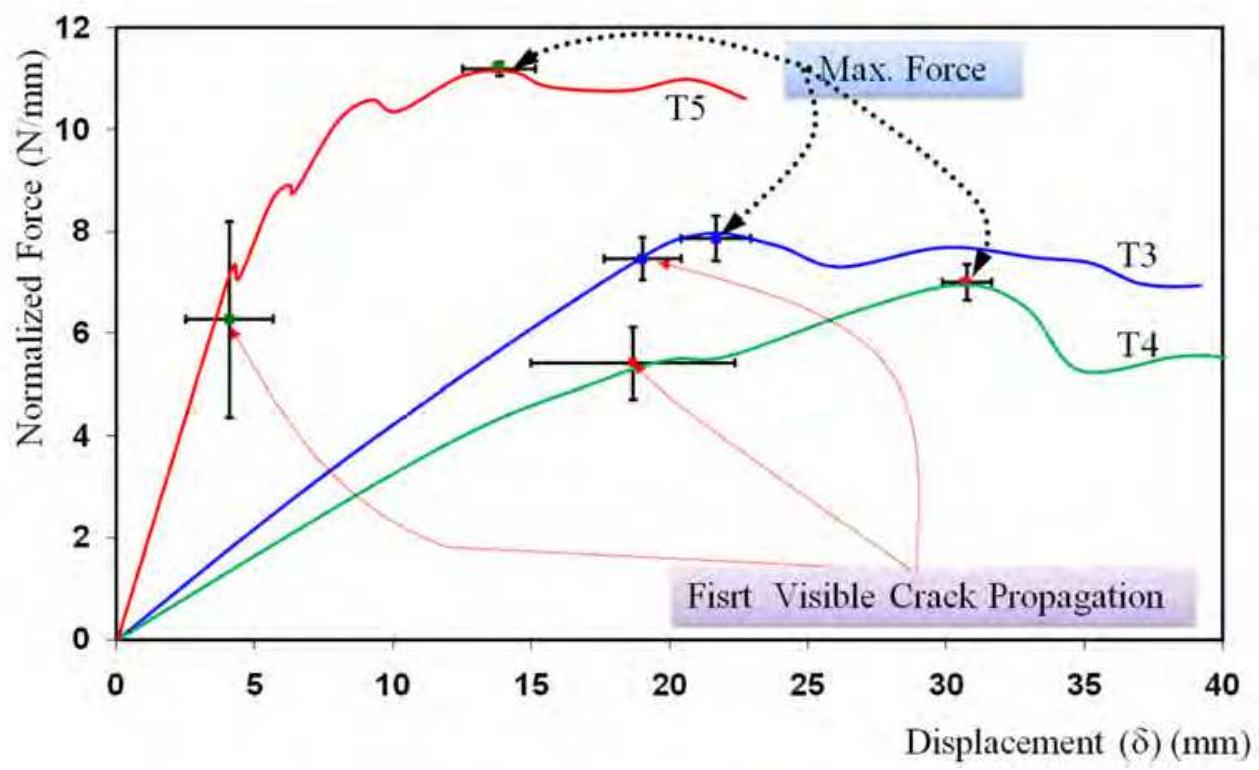

Fig. 6. Comparison of the normalized force vs. displacement diagrams for each of the three interface types with the points where there is the maximum of the force and where crack propagation begins (the confidence bars are based on the single standard deviation).

\begin{tabular}{|c|c|c|c|c|}
\hline & \multicolumn{2}{|c|}{ Count CUM } & \multicolumn{2}{c|}{ Ea CUM (J) } \\
\hline & M.V. & C.V. & M.V. & C.V. \\
\hline T3 & 10920 & $110 \%$ & $1.3 \mathrm{E}-13$ & $171 \%$ \\
\hline T4 & 244 & $49 \%$ & $3.8 \mathrm{E}-16$ & $97 \%$ \\
\hline T5 & 195 & $59 \%$ & $2.5 \mathrm{E}-17$ & $42 \%$ \\
\hline
\end{tabular}

Table 2. Count CUM and Ea CUM at the first visible crack extension.

\subsection{The sentry function application and results discussion}

The sentry function is the logarithm of the ratio between the normalized Strain Energy and the normalized Cumulative Acoustic Energy as in Equation 4. The Strain energy is calculated by using the load-displacement information, Fig. 4, and the cumulative $\mathrm{AE}$ energy is calculated as the summation of the AE event energy, Fig. 8. Both energies are normalized by the proper reference volume as previously described, Fig. 2: the reference volume to normalize the strain energy is made by the bended volume joined with the volume where the delamination grows $(\mathrm{V} 1+\mathrm{V} 2)$, the reference volume for the acoustic energy is calculated where the delamination grows (V2) considering each measurement of crack extension, see Fig. 4. 

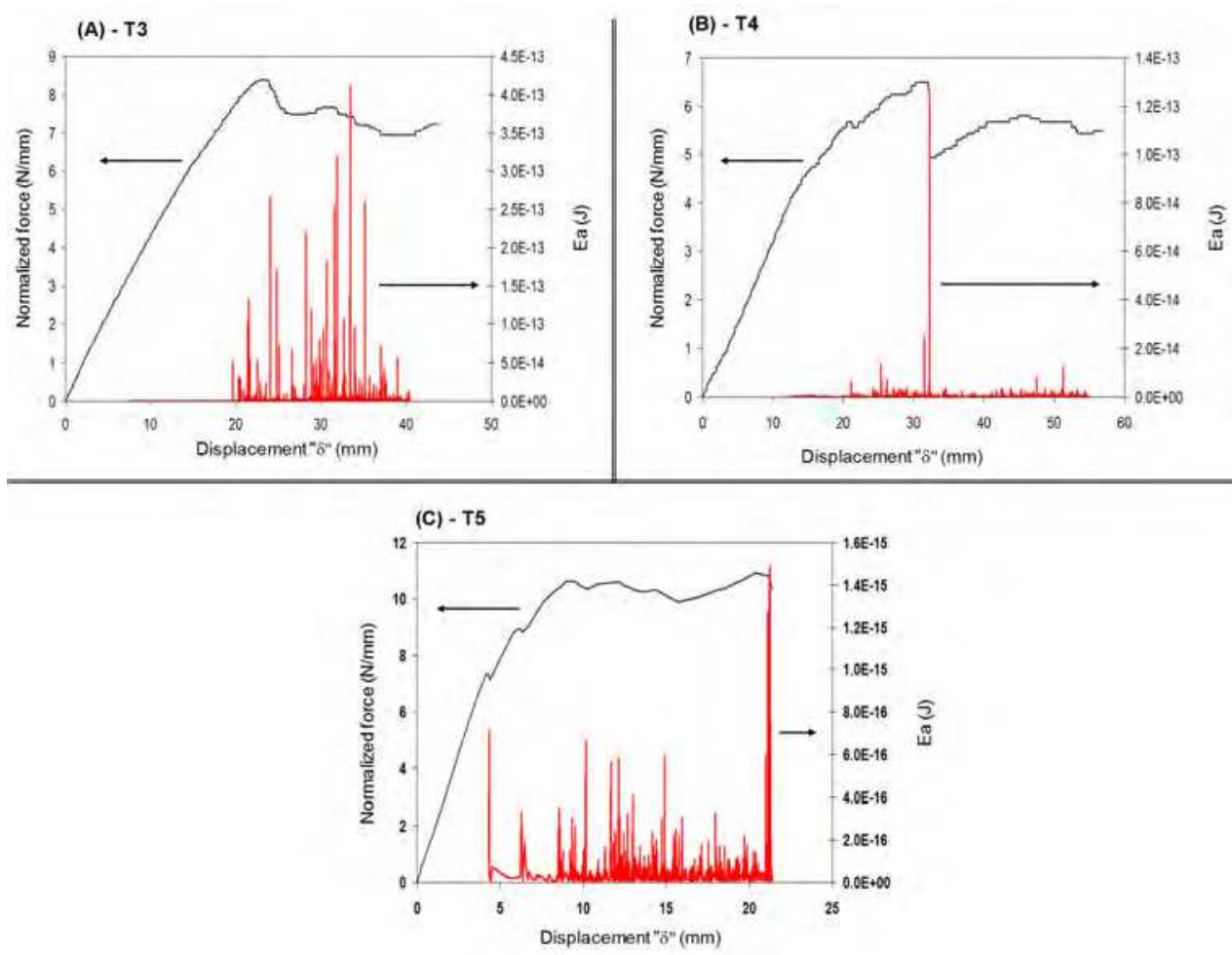

Fig. 7. Normalized load vs. displacement and acoustic energy (Ea) vs. displacement diagrams for the three types of interfaces.

In diagrams (A), (C) and (E) of Fig. 9 the single sentry function trends are highlighted according to the scheme reported in Fig. 3. The ascription of the sentry function trends to the experimental diagram of $f$ is based on the basic discussion reported in the paragraph 2.5. In particular, it is interesting to note that in the case of T3 interface types (diagram A) no BU trends are highlighted; on the contrary, this trend can be seen in the case of the other two interface types. This can be explained by the fact that in the case of T4 and T5 interface types the fiber bridging effects were experimentally observed. It can also be observed that for all interface types, the sentry function has many drops ( $\mathrm{P}_{\mathrm{II}}$ trend) but one of them is prevalent with respect to the others (the "big fall"). In the particular case of T3 and T4 interface types, the big fall occurs when the load undergoes a big drop. For the T3 and T4 interfaces, this behavior, see also diagrams (B) and (D) in Fig. 9, can be related to the abrupt change in the energy release rate $G_{I}$ and can be physically described as the test stage at which the delamination growth reaches the instability condition. In the case of the T5 interface, the big fall of the sentry function is not related to a significant load drop, but it is related to the second small load drop. So, unlike the case of the T3 and T4 interface types, the big drop of the T5 sentry function can not be related to the instable delamination growth.

Two other interesting analyses on the sentry functions can be performed by considering respectively its trends before and after the big drops and its shape with respect to the first 


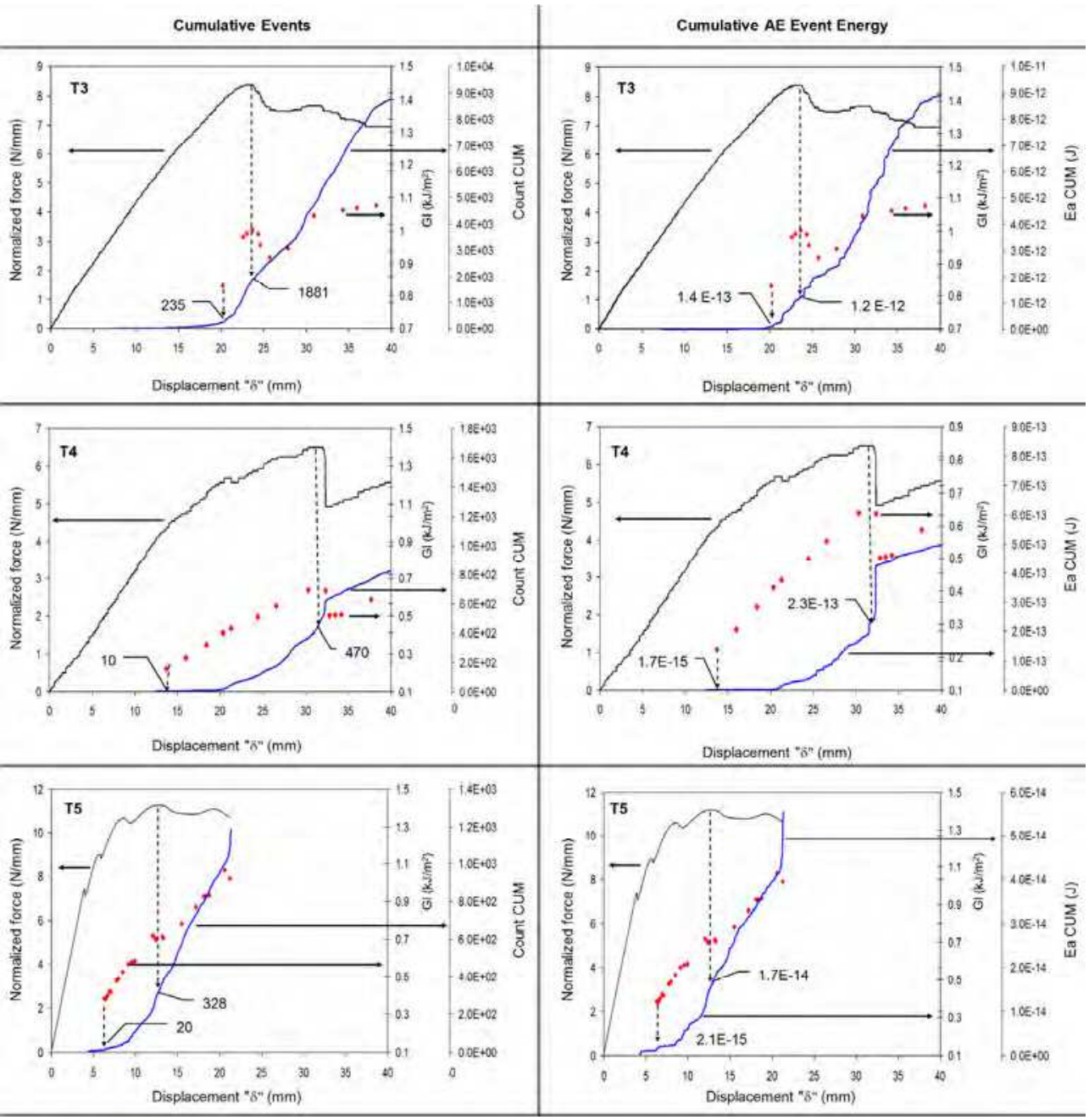

Fig. 8. Typical AE cumulative event (column 1) and cumulative AE event energy (column 2) during the delamination process for each type of interface.

visible crack propagation. Regarding the first aspect, it can be noted that, before the big fall of $f$, in the case of $\mathrm{T} 3$ and T4 specimens the sentry function trends consist of combinations of $\mathrm{P}_{\mathrm{II}}, \mathrm{P}_{\mathrm{III}}$ and $\mathrm{P}_{\mathrm{IV}}$ trends. These compositions indicate the fact that the AE released energy tends to overcome the strain energy storing capability of the material. In the case of the T4 specimen, it also has to be noted that before the big fall of the sentry function some BU trends are present. As stated previously, the BU trends highlight the presence of some fiber bridging due to the presence of a unidirectional ply in the T4 interface structure. In the case of T3 and T4 interface types, after the big drop the sentry function consists of a waved composition of $\mathrm{P}_{\mathrm{I}}, \mathrm{P}_{\mathrm{III}}$ and $\mathrm{P}_{\mathrm{IV}}$ trends. These compositions for the sentry function indicate a renewed strain energy storing capability in the material that is, in any case, partial and 

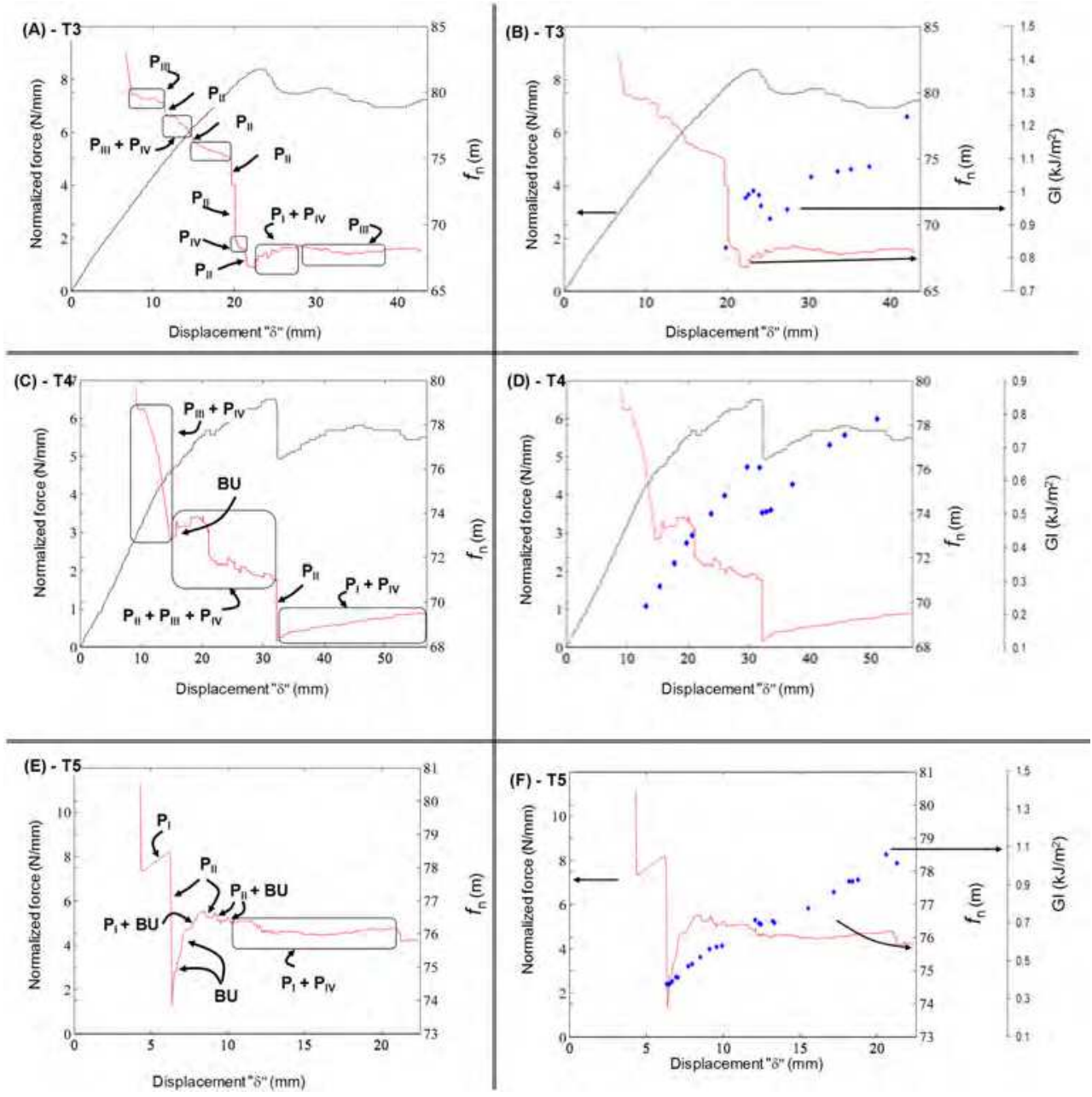

Fig. 9. Examples of sentry function trends obtained by the normalized energies in the case of woven-woven (A-T3), woven-unidirectional (B-T4) and unidirectional-unidirectional (C-T5) interface types (the load-displacement and the GI-displacement are also reported in each diagram).

discontinuous due to continuous "stop and go" progression of the post instability delamination growth process. In the case of the T5 interface type, before the big fall, the sentry function is characterized by trends of types $P_{I}$ and $P_{I I}$. These trends indicate the strain energy storing capability and the abrupt failure at the DCB specimen interface level. After the big fall, the sentry function trend of T5 specimens is characterized by the presence of $P_{I}$, $\mathrm{P}_{\mathrm{II}}, \mathrm{P}_{\mathrm{IV}}$ and BU trends. This behavior indicates the fact that, due to the fiber bridging effect, the specimen at the interface zone has a residual strain energy storing capability. In particular, this behavior is sustained until the instability growth of the delamination is reached at about $13 \mathrm{~mm}$ of displacement. After the instability of the delamination process, 
the sentry function consists of a composition of $\mathrm{P}_{\mathrm{I}}, \mathrm{P}_{\mathrm{III}}$ and $\mathrm{P}_{\mathrm{IV}}$ that is waved in shape due to the continuous "stop and go" progression of the crack front.

The second aspect concerns the relationship between the sentry function and the first visible crack propagation. The discussion is based on the fact that the sentry function simultaneously takes into account the strain energy storing capability $\left(E_{s}\right)$ and the release of the internal energy $\left(E_{a}\right)$ due to damage. So, when the energy storing capability decreases this indicates that the material damage is increased, and, at the same time, the tendency of the material to release the internal energy will decrease as well. Thus, when the material damage increases, the ratio between the energy storing capability and the cumulated released energy $\left(E_{s} / E_{a}\right)$, that is the sentry function, will decrease. The sentry function can thus be used to describe the history of the material damage. In particular, considering the integral of the sentry function over the AE displacement domain we obtain a value that is proportional to the cumulated material damage. This integral $(\operatorname{Int}(\mathrm{f}))$ can be used as a material damage indicator processes (Cesari et al., 2007; Minak \& Zucchelli, 2008; Minak et al., 2009). In fact, in previous studies, it was shown how the integral of the sentry function is related to the material damage and in particular how it can be used to predict the residual strength of composite laminate after an accident (such as an indentation or a low velocity impact phenomenon) processes (Cesari et al., 2007; Minak \& Zucchelli, 2008). Based on that observation and taking advantage of previous experiences, the integral of the sentry function in the present study is related to the test stage at which the crack propagation became visible. The aim of this analysis is to find a novel way to predict when the crack propagation became visibly detectable (a similar analysis was previously performed considering the cumulative counts and the cumulative AE energy without any success). Implementing this idea, the integral of the sentry function was calculated between the displacement at which the $\mathrm{AE}$ was revealed for the first time and the displacement at which the crack progression became visible. Obviously the first crack propagation was accurately estimated by a continuous crack tip monitoring at both specimens edges.

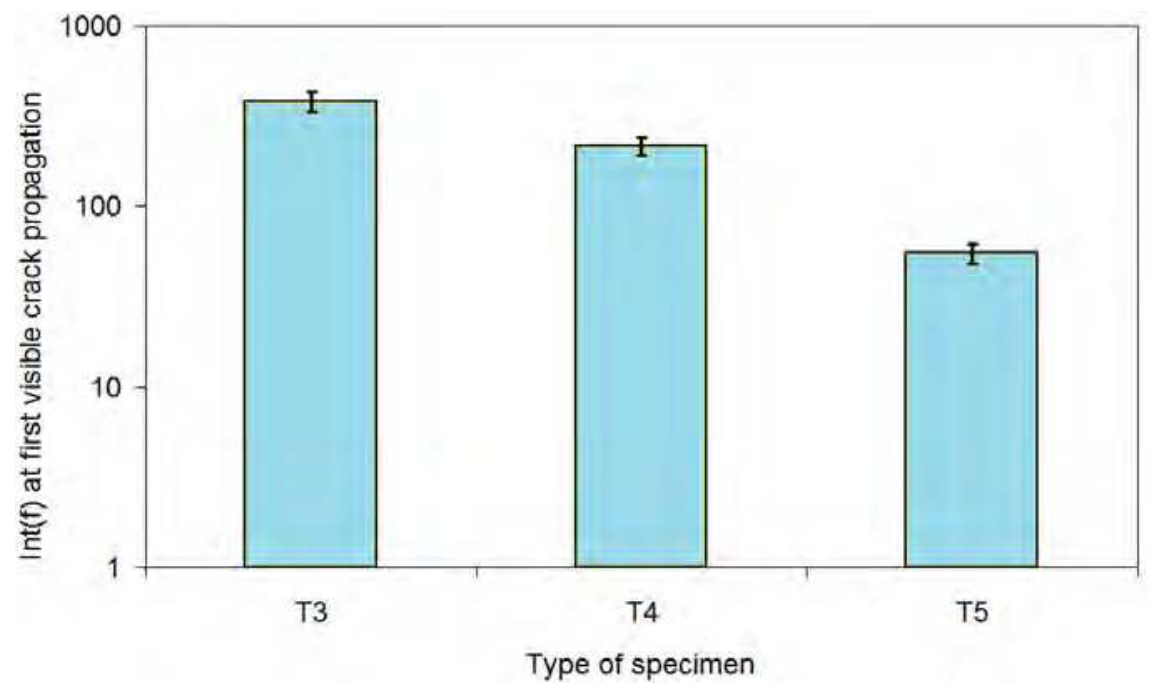

Fig. 10. Mean values and standard deviation of the integral of the sentry function between the beginning of the $\mathrm{AE}$ and the first visible crack propagation (value in log-scale). 
From Fig. 10 it can be seen that the value of the integral of the sentry function between the beginning of the $\mathrm{AE}$ and the first visible crack propagation has a very low deviation from the mean value for each type of specimen (the coefficient of variations was close to $13 \%$ ). These results indicate that for a specific type of interface the value of the integral of the sentry function can be used as an alarm, indicating when the crack propagation became visible. From the practical point of view, this way of using the Int(f) could be usefully applied to detect, in a real size structure, when a delamination crack, under a mode I loading, starts propagating.
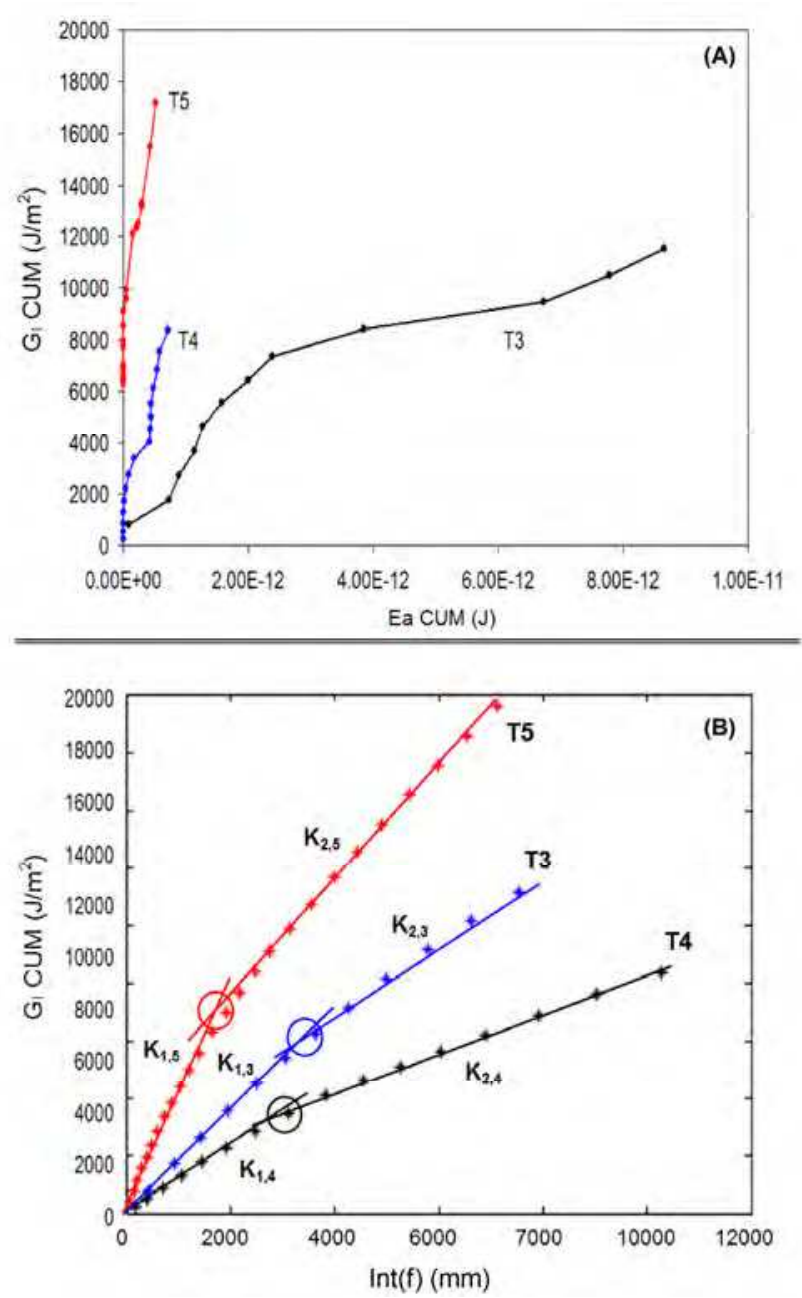

Fig. 11. (A) plot of GI CUM versus Ea CUM as proposed in Ref. (Ndiaye et al., 2000); (B) plot of cumulative $\mathrm{G}_{\mathrm{I}}$ versus integration of $f$ function, in this case the bilinear functions for each specimen type are visually characterized by means of the transition points highlighted by the circles. 
A second analysis that was performed using the sentry function concerns the relationship between the integral of the sentry function itself and the strain energy release rate. This analysis is inspired by the work of (Ndiaye et al., 2000) where the cumulative of $G_{I}$ is related to the cumulative of the AE event energy, see Fig. 11 (A); a different approach is nevertheless proposed considering the plot of cumulative $G_{I}\left(G_{I} C U M\right)$ versus the integral of the sentry function, $\operatorname{Int}(\mathrm{f})$, see Fig. 11 (B).

The plots in Fig. 11 (A) do not highlight any particular trend; however, this plot has been proposed as a basis to determine the critical stain energy release rate by means of a linear fitting of the data. On the other hand, for each plot in Fig. 11 (B), a bi-linear relationship can be found between the $\mathrm{G}_{\mathrm{I}} \mathrm{CUM}$ and $\operatorname{Int}(\mathrm{f})$ where a transition point separates the two linear trends. Our idea is that using the plots in Fig. 11(B) it is possible to estimate the critical crack length and consequently the $\mathrm{G}_{\mathrm{Ic}}$ and in the following some arguments are developed following this aim.

A preliminary observation from Fig. 11(B) concern the fact that the two variables, Int(f) and $\mathrm{G}_{\mathrm{I}} \mathrm{CUM}$, exhibit a proportionality. This fact is supported by the fact that the $\operatorname{Int}(\mathrm{f})$ is related to the material damage (Minak \& Zucchelli, 2008; Minak et al., 2009) and the GICUM is related to the ability of the material to yield the stored strain energy to create new cracked surfaces. So, both variables are related to the material damage and this support their proportionality: cumulating the material damage $(\operatorname{Int}(\mathrm{f}))$, the cumulated strain energy release rate $\left(\mathrm{G}_{\mathrm{I}} \mathrm{CUM}\right)$ increases as well. The slope of the fitting line indicates how fast the cumulated material damage influences the strain energy release rate variation during the test. So, considering the slope of the linear $K_{1, i}(i=3,4,5)$, Fig. $11(B)$, related to the specimens T3, T4 and T5 respectively, it can be observed that even if T5 interface type is supposed to be the toughest one, it is also more susceptible to the material damage than the other. This mean that $\mathrm{T} 5$ is more susceptible to the crack length extension then the other type of specimens: when and if the delamination crack is extended in the specimen, the T5 has a faster attitude to cumulate the damage and to increase the strain energy release rate than the others.

The second observation regard to the second slope of the bilinear trends shown in Fig. 11(B). In fact the analysis of the bilinear relations shown in Fig. 11(B) reveal the fact that the slope of the linear $K_{1, i}(i=3,4,5)$ before the transition point is always higher than the slope $K_{2, i}(i=3,4,5)$ after the transition point. The slope variation is due to a change of the material strength behavior respect to the delamination crack propagation. After the transition points the material exhibits reduced crack propagation strength and the slope decreases. This fact indicate that when the cumulated strain energy release rate $\left(\mathrm{G}_{\mathrm{l}} \mathrm{CUM}\right)$ increases of a small amount this cause a considerable increment in the cumulated material damage $(\operatorname{Int}(\mathrm{f}))$.

Combining the first and the second observations it is possible to note that before the transition point the linear relation between Int(f) and GICUM refers to the stable crack propagation, while after the transition point the linear relation refers to the unsteady state crack propagation. Furthermore it can be also noted that for all specimens the transition point usually occurred near the maximum load in the load-displacement plot.

It can be concluded that Int(f)- $\mathrm{G}_{\mathrm{I}} \mathrm{CUM}$ plot (Fig. 11 (B)) can distinguish the specimens with different resistance to the delamination process in mode I. 
Based on the previously developed arguments the transition point can be used to calculate the $G_{I c}$.

The critical strain energy release rate can be calculated by different techniques has proposed in standards and the literature (Ndiaye et al., 2000). Based on the ASTM D5528 standard, there are three different definitions for an initiation value of $\mathrm{G}_{\mathrm{Ic}}$ that can be evaluated during DCB testing. These include $\mathrm{G}_{\mathrm{Ic}}$ values determined using the load and deflection measured respectively (1) at the point of deviation from linearity in the load-displacement curve (NL), (2) at the point where delamination is visually observed on the edge (VIS) measured with a microscope and (3) at the point where the compliance has increased by $5 \%$ or where the load has reached a maximum value. In the present work the ASTM D5528 method (1) and (3) will be considered to calculate reference values of the $G_{\text {Ic }}$ that will be compared to the ones obtaind following the method proposed in (Ndiaye et al., 2000) and the new method based on the sentry function (Fig. 12).
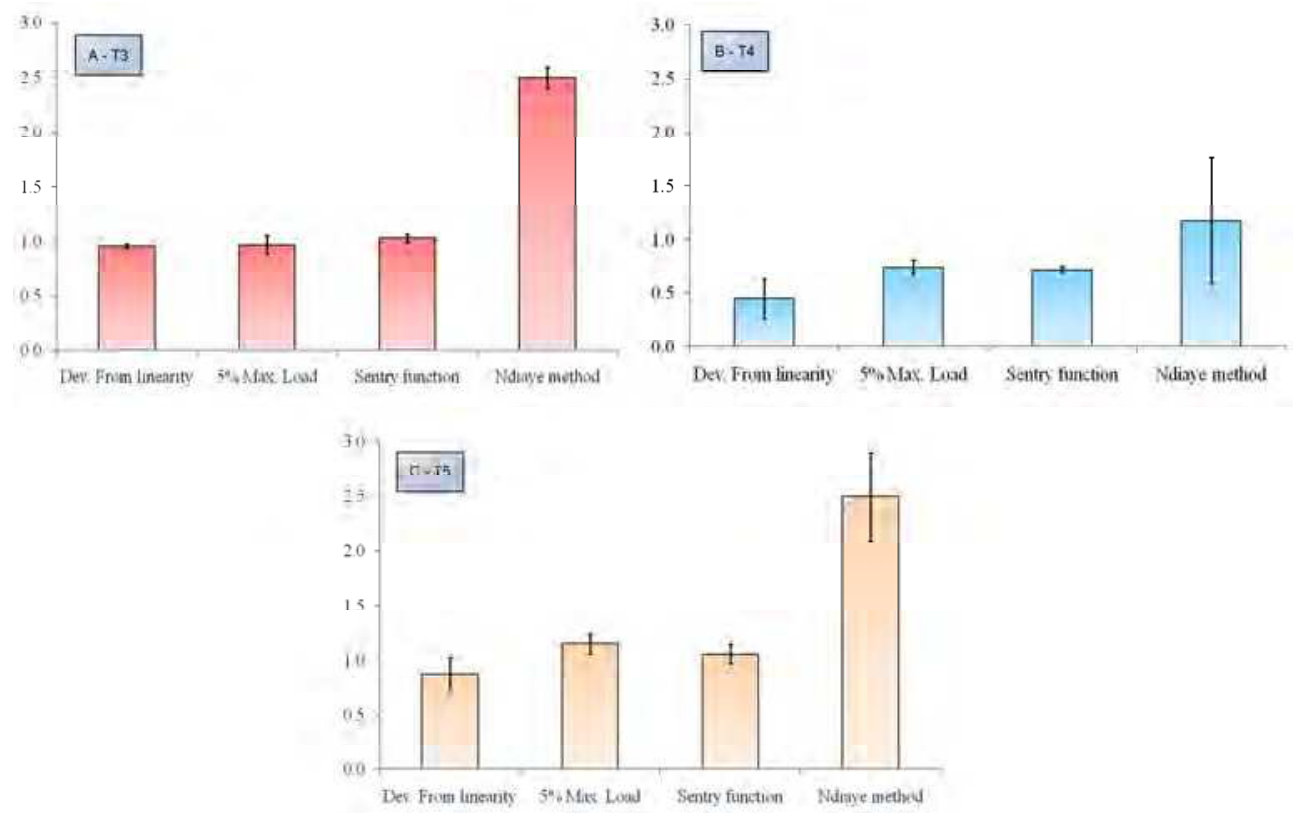

Fig. 12. Comparison between the results from the different methods for $G_{\text {Ic }}$ calculation: (A) woven-woven interface, (B) woven-unidirectional interface, $(C)$ unidirectionalunidirectional interface. 
The calculated results are obtained by finding the desired points based on the applied method. These points include propagated length of crack, displacement and the load values. For the sentry function method, $\mathrm{G}_{\mathrm{Ic}}$ is calculated by finding the knee point taking place in the $\mathrm{G}_{I}$ cumulative versus $\operatorname{Int}(\mathrm{f})$ plot. The knee point in this plot is in relation to the propagated crack length that can be found from the load-displacement plot. With regard to the crack length, the displacement point and load value of the critical strain energy release rate are calculated. Comparison between the results shows that the Ndiaye method (Ndiaye et al., 2000) has estimated $\mathrm{G}_{\mathrm{Ic}}$ values about 2 or 3 times more than the ASTM D5528 results. But $\mathrm{G}_{\mathrm{Ic}}$ calculated from the sentry function method is in good agreement with the results obtained from the ASTM D5528 method (5\% max. Load). Moreover it can be also noted that the standard deviation related to the results obtained by the new method are smaller than the ones obtained applying the ASTM D5528 methods.

It can thus be concluded that the sentry function is another alternative method for calculating $\mathrm{G}_{\mathrm{Ic}}$ directly from acoustic emission data.

\section{Conclusions}

In the present study the acoustic emission technique has been used in an unconventional way to monitor and study mode I delamination behavior of different composite laminate interfaces. The study is based on a novel function that combines mechanical information, the strain energy, and the acoustical information, the acoustic emission event energy. This function, called sentry function, is used to study the mode I delamination behavior of the three considered interfaces, and in particular it was used to identify damage progression for each interface type as well as to identify the fiber bridging events. More than this, the sentry function was also used to obtain two considerable results: the first one concerns the identification of the test stage at which the delamination propagation became visible, while the second result is a new way to estimate the $\mathrm{G}_{\mathrm{Ic}}$. The proposed approach, based on the sentry function, gives values for the $\mathrm{G}_{\mathrm{Ic}}$ of each composite interface that are in good agreement with the values estimated by means of the ASTM D5528 standard procedures. It can also be observed that the proposed method enables an estimation of the $\mathrm{G}_{\mathrm{Ic}}$ with a lower standard deviation from the mean value if compared to the results obtained by the other procedures. The main advantage of the proposed approach with respect to those in the literature is, therefore, the simple and objective identification of the test stage at which the crack delamination length became critical, thus enabling a robust calculation of the $\mathrm{G}_{\mathrm{Ic}}$ value.

\section{Acknowledgements}

The author is especially indebted to working groups in the engineering faculty and laboratory of Bologna University for valuable discussions of the problems to which the above results pertain.

\section{References}

ASTM Standard D5528. (1994). Standard Test Method for Mode I Interlaminar Fracture Toughness of Unidirectional Fiber-Reinforced Polymer Matrix Composites. 
Benmedakhene, S.; Kenane, M. \& Benzeggagh, M. L. (1999). Initiation and Growth of Delamination in Glass/Epoxy Composites Subjected to Static and Dynamic Loading by Acoustic Emission Monitoring. Composites Science and Technology, Vol.59, No.2, (February 1999), pp. 201-208, ISSN 0266-3538

Bohse, J. \& Brunner, A. J. (2008). Acoustic Emission in Delamination Investigation, In: Delamination Behaviour of Composites. S. Sridharan, (Ed.), 217-277, CRC Press, ISBN 978-1-4200-7967-8, New York

Bohse, J. (2000). Acoustic Emission Characteristics of Micro-Failure Processes in Polymer Blends and Composites. Composites Science and Technology, Vol.60, No.8, (June 2000), pp. 1213-1226, ISSN 0266-3538

Cesari, F.; Dal Re, V.; Minak, G. \& Zucchelli, A. (2007). Damage and Residual Strength of Laminated Carbon-Epoxy Composite Circular Plates Loaded at the Centre. Composites Part A: Applied Science and Manufacturing, Vol.38, No.4, (April 2007), pp. 1163-1173, ISSN 1359-835X

Chen, J.; Crisfield, M.; Kinloch, A. J.; Busso, E. P.; Matthews, F. L. \& Qui, Y. (1999). Predicting Progressive Delamination of Composite Material Specimens via Interface Elements. Mechanics of Composite Materials Structures, Vol.6, No.4, (October 1999), pp. 301-317, ISSN 1075-9417

Diaz, A. D.; Caron, J. F. \& Ehrlacher, A. (2007). Analytical Determination of the Modes I, II and III Energy Release Rates in a Delaminated Laminate and Validation of a Delamination Criterion. Composite Structures, Vol.78, No.3, (May 2007), pp. 424-432, ISSN 0263-8223

Hug G, Thevenet, P.; Fitoussi, J. \& Baptiste, D. (2006). Effect of the Loading Rate on Mode I Interlaminar Fracture Toughness of Laminated Composites. Engineering Fracture Mechanics, Vol.73, No.16, (November 2006), pp. 2456-2462, ISSN 00137944

Huguet, S.; Godin, N.; Gaertner, R.; Salmon, L. \& Villard, D. (2002). Use of Acoustic Emission to Identify Damage Modes in Glass Fibre Reinforced Polyester. Composites Science and Technology, Vol.62, No.10-11, (August 2002), pp. 1433-1444, ISSN 02663538

Kim, B. W. \& Mayer A. H. (2003). Influence of Fiber Direction and Mixed-Mode Ratio on Delamination Fracture Toughness of Carbon/Epoxy Laminates. Composites Science and Technology, Vol.63, No.5, (April 2003), pp. 695-713, ISSN 0266-3538

Kusaka, T.; Hojo, M; Mai, Y. W.; Kurokawa, T.; Nojima, T. \& Ochiaib S. (1998). Rate Dependence of Mode I Fracture Behaviour in Carbon-Fibre/Epoxy Composite Laminates, Composites Science and Technology, Vol.58, No.3-4, (March-April 1998), pp. 591-602, ISSN 0266-3538

Lorriot, T. h.; Marion, G.; Harry, R. \& Wargnier, H. (2003). Onset of Free-Edge Delamination in Composite Laminates under Tensile Loading. Composites Part B: Engineering, Vol.34, No.5, (July 2003), pp. 459-471, ISSN 1359-8368

MIL-HDBK-17-3F, (2002). Department of Defense Handbook, Composite Materials Handbook, Volume 3. Polymer Matrix Composites Materials Usage, Design and Analysis, Chapter 5, Paragraph 5.4.5, ed. 17, (June 2002). 
Minak, G. \& Zucchelli, A. (2008). Damage Evaluation and Residual Strength Prediction of CFRP Laminates by Means of Acoustic Emission Techniques. In: Composite Materials Research Progress, L.P. Durand, (Ed.), 165-207, Nova Science Publishers, ISBN 978-1-60692-496-9, New York

Minak, G.; Abrate, S.; Ghelli, D.; Panciroli, R. \& Zucchelli, A. (2010). Residual Torsional Strength after Impact of CFRP Tubes, Composites Part B: Engineering, Vol.41, No.8, (December 2010), pp. 637-645, ISSN 1359-8368

Minak, G.; Morelli, P. \& Zucchelli, A. (2009). Fatigue Residual Strength of Circular Laminate Graphite-Epoxy Composite Plates Damaged by Transverse Load, Composites Science and Technology, Vol.69, No.9, (July 2009), pp. 1358-1363, ISSN 0266-3538

Ndiaye, I; Maslouhi, A. \& Denault, J. (2000). Characterization of Interfacial Properties of Composite Materials by Acoustic Emission. Polymer Composites, Vol.21, No.4, (August 2000), pp. 595-604, ISSN 0272-8397

Niebergall, U.; Bohse, J.; Seidler, S.; Grellmann, W. \& Schürmann, B. L. (1999). Relationship of Fracture Behavior and Morphology in Polyolefin Blends. Polymer Engineering $\mathcal{E}$ Science, Vol.39, No.6, (June 1999), pp. 1109-1118, ISSN 1548-2634

Pagano, N. J. \& Schoeppner, G. A. (2000). Delamination of Polymer Matrix Composites: Problems and Assessment. In: Comprehensive Composite Materials. A. Kelly, C. Zweben, (Ed.), 433-528, Elsevier Science, ISBN 0080437206, Amesterdam

Perrin, F.; Bureau, M. N.; Denault, J. \& Dickson, J. I. (2003). Mode I interlaminar Crack Propagation in Continuous Glass Fiber/Polypropylene Composites: Temperature and Molding Condition Dependence. Composites Science and Technology, Vol. 63 No.5, (April 2003), pp. 597-607, ISSN 0266-3538

R'Mili, M.; Moevus, M. \& Godin, N. (2008). Statistical Fracture of E-Glass Fibres Using a Bundle Tensile Test and Acoustic Emission Monitoring. Composites Science and Technology, Vol.68, No.7-8, (June 2008), pp. 1800-1808, ISSN 0266-3538

Refahi Oskouei, A. \& Ahmadi, M. (2010). Acoustic Emission Characteristics of Mode I Delamination in Glass/Polyester Composites. Composite Materials, Vol.44, No.7, (April 2010), pp. 793-807, ISSN 0021-9983

Sjogren, A. \& Asp, L. E. (2002). Effects of Temperature on Delamination Growth in a Carbon/Epoxy Composite under Fatigue Loading. International Journal of Fatigue, Vol.24, No.2-4, (February-April 2002), pp. 179-184, ISSN 0142-1123

Solaimurugan, S. \& Velmurugan, R. (2008). Influence of In-Plane Fibre Orientation on Mode I Interlaminar Fracture Toughness of Stitched Glass/Polyester Composites. Composites Science and Technology, Vol.68, No.7-8, (June 2008), pp. 1742-1752, ISSN 0266-3538

Tsai, G. C. \& Chen, J. W. (2005). Effect of Stitching on Mode I Strain Energy Release Rate. Composite Structures, Vol.69, No.1, (June 2005), pp. 1-9, ISSN 0263-8223

Velmurugan, R. \& Solaimurugan, S. (2007). Improvements in Mode I Interlaminar Fracture Toughness and In-Plane Mechanical Properties of Stitched Glass/Polyester Composites. Composites Science and Technology, Vol. 67, No.1, (January 2007), pp. 6169. ISSN 0266-3538 
Wu, X. F. \& Dzenis, Y. A. (2005). Experimental Determination of Probabilistic EdgeDelamination Strength of a Graphite-Fiber/Epoxy Composite. Composite Structures, Vol.70, No.1, (August 2005), pp. 100-108, ISSN 0263-8223 


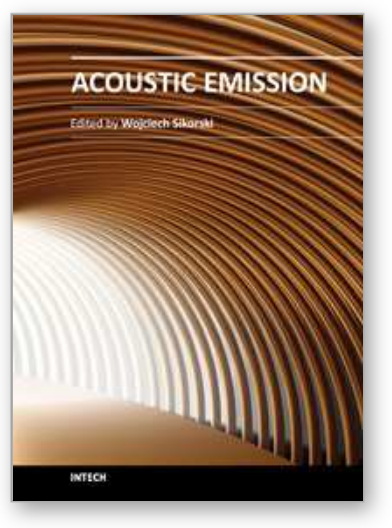

\author{
Acoustic Emission \\ Edited by Dr. Wojciech Sikorski
}

ISBN 978-953-51-0056-0

Hard cover, 398 pages

Publisher InTech

Published online 02, March, 2012

Published in print edition March, 2012

Acoustic emission (AE) is one of the most important non-destructive testing (NDT) methods for materials, constructions and machines. Acoustic emission is defined as the transient elastic energy that is spontaneously released when materials undergo deformation, fracture, or both. This interdisciplinary book consists of 17 chapters, which widely discuss the most important applications of AE method as machinery and civil structures condition assessment, fatigue and fracture materials research, detection of material defects and deformations, diagnostics of cutting tools and machine cutting process, monitoring of stress and ageing in materials, research, chemical reactions and phase transitions research, and earthquake prediction.

\title{
How to reference
}

In order to correctly reference this scholarly work, feel free to copy and paste the following:

Amir Refahi Oskouei, Andrea Zucchelli, Mehdi Ahmadi and Giangiacomo Minak (2012). Using Acoustic Emission to Evaluate Fracture Toughness Energy Release Rate (GI) at Mode I Delamination of Composite Materials, Acoustic Emission, Dr. Wojciech Sikorski (Ed.), ISBN: 978-953-51-0056-0, InTech, Available from: http://www.intechopen.com/books/acoustic-emission/using-acoustic-emission-to-evaluate-fracture-toughnessenergy-release-rate-gi-at-mode-i-delamination

\section{INTECH}

open science | open minds

\section{InTech Europe}

University Campus STeP Ri Slavka Krautzeka 83/A 51000 Rijeka, Croatia Phone: +385 (51) 770447 Fax: +385 (51) 686166 www.intechopen.com

\section{InTech China}

Unit 405, Office Block, Hotel Equatorial Shanghai No.65, Yan An Road (West), Shanghai, 200040, China 中国上海市延安西路65号上海国际贵都大饭店办公楼405单元 Phone: +86-21-62489820

Fax: +86-21-62489821 
(C) 2012 The Author(s). Licensee IntechOpen. This is an open access article distributed under the terms of the Creative Commons Attribution 3.0 License, which permits unrestricted use, distribution, and reproduction in any medium, provided the original work is properly cited. 